\title{
'Clearer and better': preferences of children with reading difficulties for the typography and illustration in literacy materials
}

Article

Published Version

Thiessen, M. and Dyson, M. C. (2010) 'Clearer and better': preferences of children with reading difficulties for the typography and illustration in literacy materials. The International Journal of Learning, 16 (12). pp. 365-384. ISSN 1447-9494 Available at https://centaur.reading.ac.uk/17720/

It is advisable to refer to the publisher's version if you intend to cite from the work. See Guidance on citing.

Published version at: http://ijl.cgpublisher.com/product/pub.30/prod.2553

Publisher: Common Ground

All outputs in CentAUR are protected by Intellectual Property Rights law, including copyright law. Copyright and IPR is retained by the creators or other copyright holders. Terms and conditions for use of this material are defined in the End User Agreement. 


\section{CentAUR}

Central Archive at the University of Reading

Reading's research outputs online 


\section{The International JOURNAL \\ LEARNING}

Volume 16, Number 12

'Clearer and Better': Preferences of Children with Reading Difficulties for the Typography and Illustration in Literacy Materials

Myra Thiessen and Mary C. Dyson 
THE INTERNATIONAL JOURNAL OF LEARNING

http://www.Learning-Journal.com

First published in 2010 in Champaign, Illinois, USA by Common Ground Publishing LLC www.CommonGroundPublishing.com.

(C) 2010 (individual papers), the author(s)

(c) 2010 (selection and editorial matter) Common Ground

Authors are responsible for the accuracy of citations, quotations, diagrams, tables and maps.

All rights reserved. Apart from fair use for the purposes of study, research, criticism or review as permitted under the Copyright Act (Australia), no part of this work may be reproduced without written permission from the publisher. For permissions and other inquiries, please contact <cg-support@commongroundpublishing.com>.

ISSN: 1447-9494

Publisher Site: http://www.Learning-Journal.com

THE INTERNATIONAL JOURNAL OF LEARNING is peer-reviewed, supported by rigorous processes of criterion-referenced article ranking and qualitative commentary, ensuring that only intellectual work of the greatest substance and highest significance is published.

Typeset in Common Ground Markup Language using CGCreator multichannel typesetting system

http://www.commongroundpublishing.com/software/ 


\title{
'Clearer and Better': Preferences of Children with Reading Difficulties for the Typography and Illustration in Literacy Materials
}

\author{
Myra Thiessen, University of Reading, UK \\ Mary C. Dyson, University of Reading, UK
}

\begin{abstract}
Preference influences how an individual chooses graphic material and is therefore an important consideration in the design of literacy materials for children with reading difficulties, such as those associated with dyslexia. However, little is known about what this group of children like and dislike about the typography and the illustrations in their reading materials. Children with reading difficulties are likely to be less motivated to practise their literacy skills, and as fluency in literacy can only be gained through practice, it is important to understand how reading materials can be created that these children will be more motivated to read. Through case-studies of six children with reading difficulties, their typographic (parts one and two) and illustrative (part three) preferences were tested. Parts one and two were concerned with the effects of typesetting and looked at the influence of letter, word, and line spacing, and also type size. The typographic preferences of these six children were analysed and were then compared to their reading performance. Part three focused on the illustrative preferences of these children and looked at the use of colour and the level of detail included in this kind of visual information. By creating reading materials that correspond to the preferences of children with reading difficulties it is more likely that they will be motivated to read those books. These casestudies are part of ongoing research into the development of alternative materials for teaching literacy skills to children with dyslexia.
\end{abstract}

Keywords: Literacy, Dyslexia, Typography, Illustration, Design

$\mathrm{M}$ OTIVATION TO PRACTISE is a key factor in learning to read. If a child is not willing to practise they are unlikely to develop into a fluent reader (Byrne, 2007). Children who suffer reading difficulties, such as those associated with dyslexia, are less likely to be motivated to practise as their slowed literacy development is often at the heart of a poor self-image and a disbelief in their own ability to learn (Burden and Burdett, 2005). Too often the children who require the most practice are spending the least amount of time with books.

Children, even at a young age, have shown that they have clear opinions about the typography in their reading books and that these opinions may influence their motivation to choose particular reading material (Walker and Reynolds, 2002/03; Reynolds and Walker, $2004 ; 2006$ ). Considering the preferences of children is an important part of designing literacy materials for them and maintaining that balance between what they want to read and what they can read. However, relatively little is known about what children with reading difficulties think about their literacy material. Creating books that consider the preferences of this group will no doubt increase the time they spend reading.

The International Journal of Learning

Volume 16, Number 12, 2010, http://www.Learning-Journal.com, ISSN 1447-9494

(C) Common Ground, Myra Thiessen, Mary C. Dyson, All Rights Reserved, Permissions:

cg-support@commongroundpublishing.com 
Recent typographic research into the design of literacy materials for children with reading difficulties, such as those associated with dyslexia, has focused on typeface development (Frensch, 2003; Castle, 2004; Hillier, 2006), but it may not be beneficial, or realistic, to limit the number of typefaces children are exposed to when learning to read. The ability to read a variety of different typefaces may be an important part of developing into a fluent reader and it may be more beneficial to understand the influence of how those letters are typeset. Elements such as the size of the type, the space that exists between the letters, words, and lines, the weight of the typeface and even the use of uppercase letters may influence both the legibility of the text and the motivation of children to read it.

Children's reading books are generally designed with a large type size to aid with letter and word identification. As a child's literacy ability develops this type size is rapidly decreased until their texts more closely resemble those designed for fluent readers, generally around the age of nine or ten. This decrease in type size coincides with an increased complexity in both the syntactic and semantic structure of text and may unduly increase reading difficulty (Hughes and Wilkins, 2000).

The amount of space between letters, words, and lines can also have an impact on letter discrimination as increased spacing can influence the perceived clarity and size of letterforms. Reynolds and Walker (2004) looked at the influence of letter and word spacing on the reading performance of beginning readers, and although this study did not show significant differences in reading performance, it did show that the children's perception of widely spaced text was that it appeared clearer than narrowly spaced texts of the same size. Hughes and Wilkins (2002) reported a similar result in their study that looked at distance reading with Big Books ${ }^{1}$.

Reading materials designed for children who struggle with literacy acquisition are difficult to find, but publisher Barrington Stoke (www.barringtonstoke.co.uk) has taken initiative and targeted this niche market. Unique to Barrington Stoke's 4u2read.ok series is the exclusive use of a heavy weight typeface. Traditionally heavy weight typefaces have been reserved for creating emphasis within texts, but in this series Barrington Stoke uses this form to typeset the main body of the text. Although the intentions of Barrington Stoke for producing the series of books this way are not known, their aim may be to strengthen letter discrimination by increasing the contrast of the letter on the page (Thiessen, 2007). Further research is needed on whether this approach is beneficial for children with reading difficulties.

Barrington Stoke avoids the use of uppercase letters as much as possible suggesting these less familiar letterforms may confuse struggling readers (Thompson, 2003). However, uppercase letters are larger, contain more unique letter features, and have proven to be more visible than lowercase (Tinker, 1963; Watts and Nisbet, 1974) warranting the question whether children with reading difficulties would benefit from the use of uppercase letterforms in their reading books.

In contemporary literacy materials illustrations are normally a dominant feature, especially in those created for young readers, but research results have shown disagreement on the role they play and just how effective they are. On the one hand the use of illustrations may hinder literacy development by distracting new readers from the verbal information; on the other, and as seen in contemporary literature, illustrations are viewed as an important part of literacy

\footnotetext{
${ }^{1}$ Big Books are commonly used in classrooms for group reading. They are large format books that have been designed for distance reading. Typically several children will be expected to read from a single book.
} 
development by providing valuable representational and supplemental information that cannot always be included in the text due to verbal complexity (Carney and Levin, 2002). Whatever the role of the illustration, it should be a clear and accurate interpretation of the verbal information it supports or it could confuse rather than help readers (Arnheim, 1969; Goldsmith, 1984; Levin et al., 1987; Peeck, 1987; Newton, 1995; Carney and Levin, 2002).

In classrooms children are active in choosing which books they read, but what do they base these choices on? Relatively little is known about what children think about the design of their reading materials: what they think looks easier to read, what they find easier to understand, and what they find aesthetically pleasing. It is important to consider these aspects as increasing motivation is likely to increase the amount children read, and the amount a child reads has been linked to both their academic and social success (Cox and Guthrie, 2001).

In an attempt to inform the creation of literacy materials that children with reading difficulties will like, find easier to understand, and will be more motivated to read, six children were interviewed over ten weekly sessions and their preferences for typography and illustration in their literacy materials were analysed. In addition, each child took part in a reading performance task that supplemented the data collected during the preference portion of this study. What resulted were six in-depth case-studies that show what this group of children prefer, and that the reading materials developed for them do not always reflect these preferences.

\section{Method}

This study was broken down into three parts. Parts one and two looked at the effects of typography on the children's preferences and reading performance respectively, and are discussed together below under the heading 'Typography'. In the third part, preference for illustration was the focus. The same children participated in all three parts of this study, which ran for ten weekly sessions, and an in-depth case-study was developed for each child.

Qualitative studies are unique in that they are able to provide perspective that quantitative methods cannot, and the study of literacy and literacy materials benefits greatly from this approach. Qualitative studies provide valuable information about readers, and how they use, interact, and think about the books they are reading (Hinchman, 2005), which can aid in the generation of more useful literacy materials.

During each session the children were interviewed on a one-to-one basis. In each session they performed a series of tasks that analysed their preferences and the reliability of those preferences. Due to the intensive time investment needed to develop case-studies participant numbers are generally lower than what is seen in studies that look strictly at quantitative data. In this case it was anticipated that participant numbers would be low due to the specialised nature of reading difficulty and the literacy level of the children involved. For this reason producing intensive case-studies was a viable option. Although linguistic aspects of children's literacy materials are an important consideration for both reading ability and motivational factors, they were not of relevance here. This study was concerned only with specific aspects of the presentation of the content, both visual and verbal, in children's literacy materials. 


\section{Participants}

Only children who had English as a first language were recruited for this study. Three boys and three girls between the ages of seven and nine who experience difficulties with literacy acquisition participated in all three parts of this study. They were divided into two groups based on literacy level. Group 1 consisted of Chloe and Ethan who read at a keystage one level. In Group 2 were Emma, Lily, Max, and Joshua reading keystage 2 material ${ }^{2}$. The children were all bright and lively, but struggled with their literacy development, which was well behind that of their peers. In most cases these children were regularly removed from their classrooms for extra literacy lessons.

\section{Typography}

\section{Materials}

When looking at preference it is important that test material looks like the finished product, which in this case is a reading book. If it does not the preferences indicated may speak more about the test material than about reading books in general. The material used in the preference portion of this study resembled, as closely as possible, real reading books. Three existing age appropriate stories were chosen for each group and used to develop twelve variations in typesetting ${ }^{3}$. These variations were broken down into four sets of three alternatives. Sets 1,2 , and 3 looked at the effects of letter, word, and line spacing, and Set 4, at the size of the type. Details about the specification can be seen in Appendix 1; in summary they were: sentence case-regular, uppercase-regular, sentence case-heavy, and size.

These variations did not test the boundaries of legibility but rather questioned the children's preference for solutions that may reasonably appear in a reading book designed for their literacy level. It also did not question which typeface the children thought was most legible and for that reason a single typeface was chosen for each group and used throughout the study. Shown in figures 1 and 2, the children in Group 1 saw material typeset with Sassoon Primary Infant, and Group 2, Bembo. Commonly used in reading materials developed for these two literacy levels, these typefaces were chosen because the children were likely to be familiar with them.

\footnotetext{
2 The names of all the participants were changed to protect their identities.

${ }^{3}$ Permission to use each of the texts in this way was granted by the publishers of the stories.
} 


\section{The big, bad wolf went up to the house of bricks. "Little pig, little pig, let me come in," he said.}

Figure 1: Sassoon Primary Infant. Example from test material designed for Group 1 (text is quoted from: Ladybird's The Three Little Pigs, 2006; p. 20)

\section{"Oh," said Mr Grimble with care.}

\section{He moved slowly across to the window.}

\section{He opened it softly, while Mad Iris watched him with a beady eye.}

Figure 2: Bembo Regular. Example from test material designed for Group 2 (text is quoted from: Strong, 2002; p. 24)

For the reading performance portion of this study, the children were asked to read passages of text typeset using the same typographic variables as were used in the preference portion. Each passage was presented on a single sheet of A4 sized paper. Words were chosen based on literacy level; six words were used to create the passages of text for the children in Group 1 and ten for the children in Group 2. Words were chosen that the children were likely to be familiar with and that were orthographically regular.

The Rate of Reading Test (Wilkins, 2003) was used as a model for generating these passages of text with certain aspects adjusted to produce materials that were appropriate for the literacy level of the two groups of children that were involved in this study. In the Rate of Reading Test a series of words are typeset in a different random order for each line of text to create a passage that has no semantic meaning, an example of which can be seen in figure

3. The randomisation of words in this way means that the reader cannot use the context of 
the passage to guess at words and they must read every word. They are also unlikely to notice if they make errors while reading (Wilkins 2003), making a miscue analysis an effective supplement to this study. In a miscue analysis the number and type of errors an individual makes while reading a passage of text are analysed and can provide information about how differences in typesetting influence the ease with which an individual is able to read a given passage (Walker and Reynolds, 2002/03).

\section{flop bite dog net sun at dog sun at bite net flop at dog flop sun bite net bite sun flop net at dog net dog at bite sun flop flop sun net bite at dog sun flop net dog bite at}

Figure 3: Example of a text passage used with the children in Group 1 during the reading performance study

\section{Procedure}

The preference portion of this study ran for three weekly sessions. In each session the children were shown all twelve variations to the typesetting in groups of three. For each group the children were asked which variation they thought was the easiest to read and which they liked the look of best. This procedure was then repeated over the three weekly sessions with a different story used in each session. The task was repeated in this way to test the reliability of the preferences indicated by each child. Consistent responses in each of the three sessions indicate a strong preference, whereas a different response in each session was interpreted as no real preference. The test material was shown in a different random order to each child.

During the performance study, which ran for four weekly sessions, each child was asked to read from three passages of text for two minutes each. The reading rate was measured by 
counting how many words were read in the allotted two minutes and the overall reading performance considered both the reading rate and the number of miscues for each passage. This procedure was then repeated in each session, a different set (either sentence case-regular, uppercase-regular, sentence case-heavy, or size) used in each. Again, the test material was presented to each child in a different random order; both the order of the set and each variation within that set were randomised.

\section{Results}

Both groups of children were easily able to identify the typographic differences that existed in the texts they were shown, but they did not always identify the correct variable. On several occasions differences in spacing were identified as differences in size or in the weight of the type, but differences in size were generally identified as such by all of the children. The only exception was Lily who thought that this variation also differed in weight and spacing. Both groups also showed more reliable preferences for size than for spacing, which indicated that this was a stronger and more noticeable variable.

The children in Group 1, who were younger and less able readers than the children in Group 2, showed reliable preferences for spacing, but they did not always agree on which variations were the easiest to read or that they preferred the look of best. Ethan stated that he preferred the standard size to the small and large sizes, and Chloe, the large. Ethan and Chloe shared the opinion that the small size 'would be very, very small and you wouldn't be able to read it'. However, as can be seen in figure 4, it was with this variation that these children produced the strongest reading performance indicating that this passage was read faster and with fewer miscues.

Size

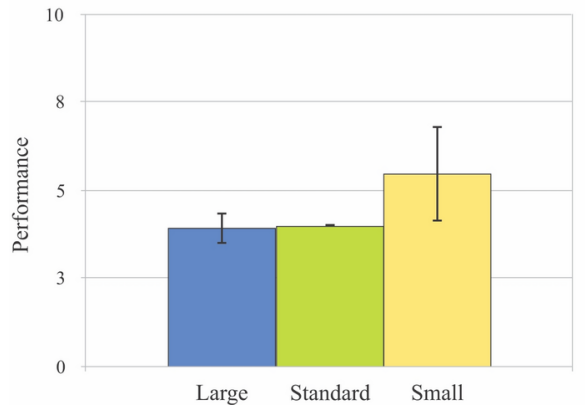

Spacing

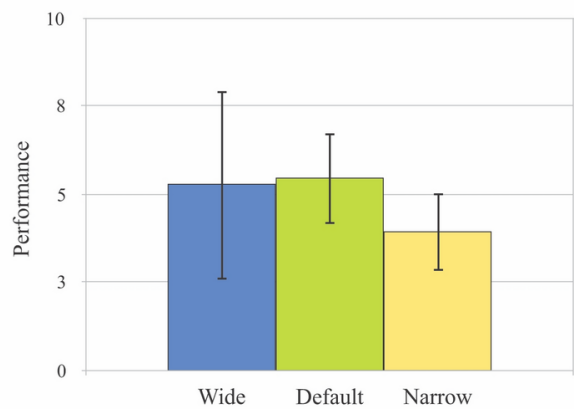

Figure 4: Reading performance of Group 1. The coloured bars indicate the group's mean reading performance for each variable. The secondary black bars show the standard error of the mean, which is an indicator of the amount of variation across children in their performance

The preferences shown by Ethan and Chloe were less reliable for the spacing variables, but they did tend to agree on which variations they thought were the easiest to read and which they liked the look of best. Both children indicated that they thought the wide options would be the easiest to read and that they liked the look of the default setting the best. These preferences were consistent with their reading performance, which showed virtually identical results with these two variables. 
When asked which variation they think is the easiest to read, it may be expected that children who have trouble with their literacy development would choose the texts that are typeset in ways that are conventionally easier: large type size. However, the children in Group 2 showed a stronger preference for the conventionally more difficult small type size, commenting, 'it's really clear to me' and, 'I could read small stuff really, the best'. During the time spent with these children it was clear that they were aware of typographic convention and what differences exist between books that less able children read compared to what an individual who is a fluent reader may choose. Emma stated when comparing type size, 'I used to be on this book, then it started to get too easy for me and I moved onto these sort of books, 'cause it gets smaller each time'. This sensitivity may be what guided the response of the children in Group 2 to select the conventionally harder texts as they may have wanted to give the impression that they did not struggle with their literacy development. Lily stated that she did not know what about the smaller type was easier, but that, 'it just seems to me that it's easier'. This may be a surprising result, but it is consistent with their reading performance. Seen in figure 5, the reading performance of this group of children was strongest with the small type size.
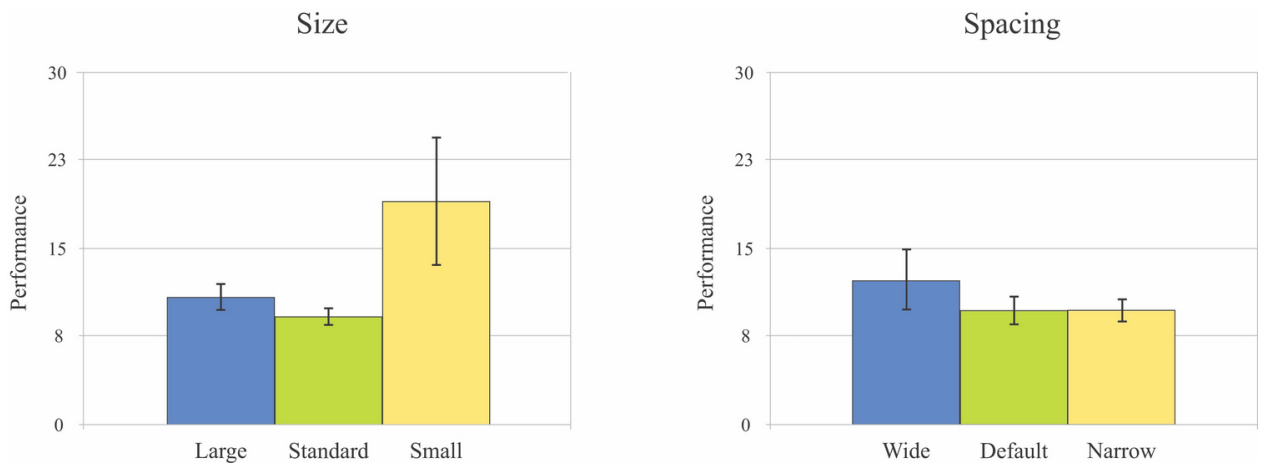

Figure 5: Reading performance of Group 2. The coloured bars indicate the group's mean reading performance for each variable. The secondary black bars show the standard error of the mean, which is an indicator of the amount of variation across children in their performance

While the children in Group 2 showed a stronger preference and had better reading performance for the conventionally harder small type size, their preference for spacing was for the conventionally easier widely spaced variations. Interestingly, their reading performance was the weakest with the most conventional standard type size and with the default spacing, which showed the same level of performance as the more difficult narrowly spaced variations. Details of each child's preferences are provided in Appendix 2.

\section{Illustration}

\section{Materials}

As with the preference for typography portion of this study, it was important to use test material that closely resembled a format that the children were familiar with for this portion of the study. In this case flashcards were the most viable solution. Flashcards are commonly used for teaching vocabulary and generally contain a single word and a visual explanation 
of that word. For this study this simple format was used but all verbal information was removed concentrating the children's attention on the illustration.

Three words were chosen for each group that were appropriate for their literacy level and were likely to be part of their verbal vocabulary. Rather than use concrete nouns, as is typically done with this form of literacy material, words that have abstract meaning and are difficult to visualise were intentionally chosen. These words may be more difficult to learn due to their abstract nature and by providing visual explanations it may improve the ease with which children with reading difficulties are able to acquire these words. Group 1 were shown visual explanations for more, some, and even, and Group 2, straight, whole, and neither.

Focusing on preference for colour and for the level of detail present in the illustration, four variations were created: colour-representative, colour-stylised, greyscale-representative, and greyscale-stylised. Figure 6 shows an example of the four variations for the concept more.
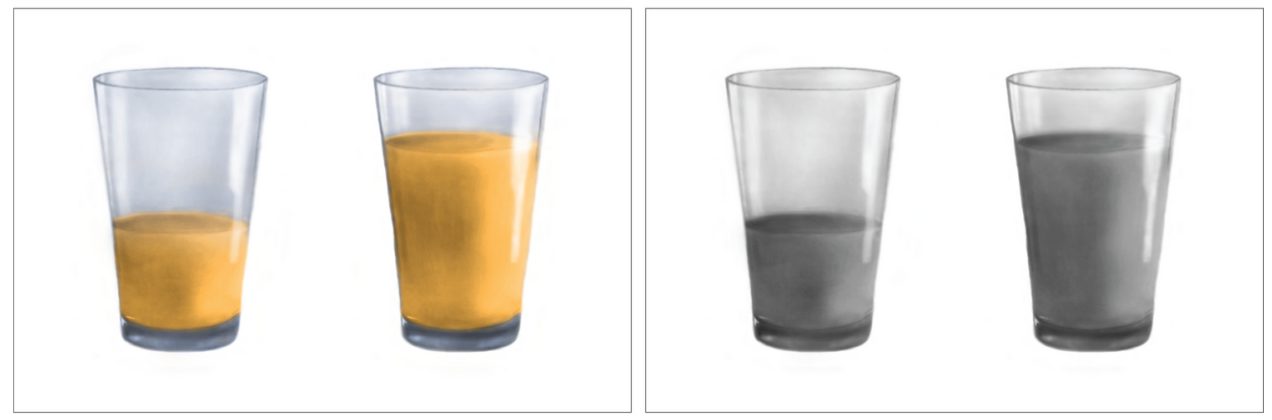

Colour-representative

Greyscale-representative
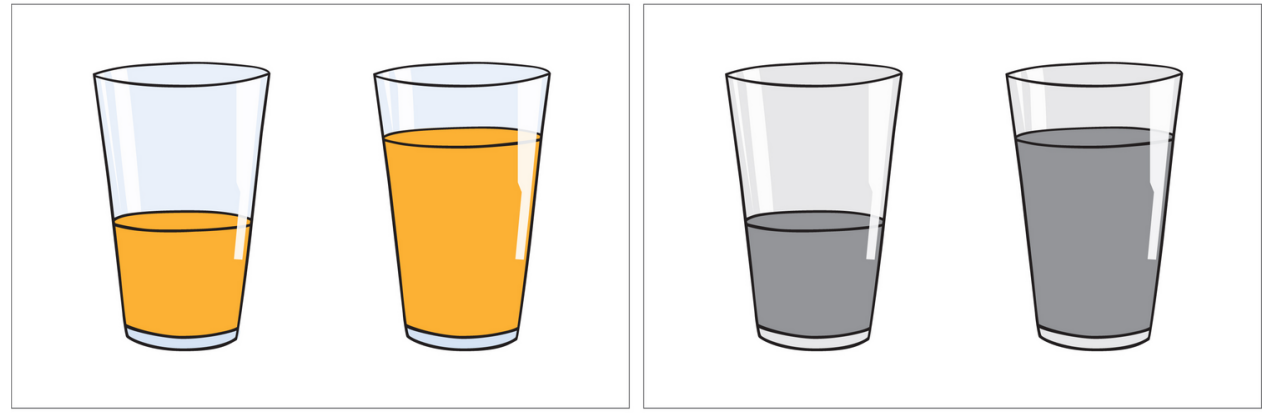

Colour-stylised

Greyscale-stylised

Figure 6: Four variations of a visual explanation for the complex verbal concept more

\section{Procedure}

The same general procedure outlined above for the typographic preference study was followed here. This study ran for three weekly sessions and in each session the children were shown four variations of the same visual explanation in groups of two. For each pair they were asked to chose which variation they thought was the clearest or the easiest to understand, which they would choose to help them explain the meaning of the word to their classmates, 
and which they liked the look of the best. Each child was also encouraged to talk about why they made their choice and what they liked or disliked about the illustration. This procedure was then repeated for each session, only the complex verbal concept and related visual explanation changed. The material was shown to each child in a different random order; the order of the concepts, the pairs, and each variation were randomised.

\section{Results}

The preferences indicated by the children in Group 1 showed that they considered colour to be a valuable visual cue in helping them identify objects within an illustration. Both Ethan and Chloe showed a strong preference for the colour options when asked which variation they thought was the clearest and which they would choose to help them explain the meaning of the word to their classmates. Chloe also preferred the colour variations to the greyscale for aesthetic appeal stating, '[colour] makes you like it more'. However, Ethan did not show a reliable preference for either the colour or greyscale variations. Although this was interesting to note, it was not thought to be representative of Ethan's opinion. In discussion with Ethan it was clear that he liked the ambiguity of the greyscale images and made a game of imagining what these images could be when the colour was not there to help him identify the objects. For example, the visual explanation of the verbal concept some was a bag of oranges. Ethan stated he preferred the aesthetic appeal of the greyscale variation because, 'they look like boulders coming out of a bag', but went on to comment, 'I know that one's oranges more than that one ...'cause it's in colour'.

When looking at the level of detail, both Ethan and Chloe preferred the representative variations to the stylised when asked about the clarity of the images, but the preferences indicated here were not as reliable as those for colour. They also thought that the representative variations were clearer and were the variations they would chose to help them explain the meaning of the words to their classmates. When it came to the aesthetic appeal of the illustrations Ethan showed a strong preference for the stylised variations, stating that he liked to watch cartoons, and as the stylised illustrations reminded him of cartoons he preferred the look of them to the representative images. Chloe did not show a reliable preference for either the representative or the stylised variations when she was asked which one she liked the look of best.

Although there were more children in Group 2 than Group 1, there was less variation in their preferences as a whole, which may be a result of their age and literacy level. The children in Group 2 showed a reliable preference for the colour variations when compared to the greyscale for the clarity of the image, the variation they would choose to help them explain the meaning of the word, and the aesthetic appeal. Although this preference was very reliable, it was less so for the stylised variations than for the representative. In addition, Emma stated on three occasions and Lily once, that they did not find the use of colour improved the clarity of the images. They did however, think that the colour would help others and selected the colour variations when asked which variation they would choose to help them explain the meaning of the words to their classmates. Finally, when looking at the level of detail a reliable preference was also observed in Group 2 for the representative variations over the stylised, and was the strongest when the children were asked which variation they liked the look of best. Details of the preferences indicated by each child can be seen in Appendix 3. 


\section{General Discussion}

All the children who participated in this study were aware of and able to identify the differences in the typesetting that existed in the test material they were shown. The younger and less advanced children in Group 1 identified the correct variable more often than the children in Group 2. As there were only two children in Group 1, it is difficult to know whether this trend would be seen across a larger sample of children. Regardless of this fact, it is important to note that all the children who participated in this study were aware of typographic convention and had opinions about what they thought looked easier to read and what they liked the look of best. It is these preferences that are likely to influence what books these children will choose to read, but are not always reflected in the materials designed for them. Literacy materials for children are designed by fluent readers with little or no consultation with their audience and as a result certain conventions have been established that are believed to be easier, such as large type sizes, but this may not be the case.

While the children in Group 1 preferred books that looked like those that resemble typical reading books designed for their ability, the children in Group 2 preferred typesetting that more closely resembled what a fluent reader would choose. This trend seen in Group 2 for typographically more difficult books may be the result of their exposure to a wider range of literacy materials than the children in Group 1 . The children in Group 2 were generally older than the children in Group 1 and the gap between themselves and their typically developing peers is larger; a gap that magnifies itself in the differences that exist in the graphic presentation of literacy materials designed for less able and more able readers. These differences become increasingly obvious as children get older, and their shortcomings in literacy more apparent. As a result, they may choose to not read at all rather than read books that look 'babyish' compared to those of their fellow classmates.

Considering their sensitivity to typographic convention it is not surprising that the children in Group 2 stated they would prefer to read the books that looked to be more advanced; however, an interesting trend was also seen in their reading performance: the children performed better with the conventionally more difficult small type size. In fact, this trend was seen with both Group 1 and Group 2. Further research is needed with a larger sample of children with similar reading difficulties before any conclusions can be drawn, but it can be noted that this group of children were reading better with the texts that they said they wanted to read.

Increasing the space between the letters, words, and lines can change how the text is perceived and children have reported that widely spaced text appears larger, lighter, and clearer than narrowly spaced type of the same size (Hughes and Wilkins, 2002; Reynolds and Walker, 2004). Therefore, it is interesting, considering the preferences that were indicated for the small type size, that the children who participated in this study also stated a general preference for the widely spaced variations. This could be because these variations look like texts generated for their more able peers, but have improved letter and word clarity.

Whereas large differences were seen between the preferences indicated by the children in Group 1 and Group 2 for typography, there do not seem to be such radical differences in their preferences for illustration, and overall, both groups thought that the colour-representative variations were the clearest and were the options they would choose to help them explain the meaning of the words to their classmates. A child's experience and knowledge of their environment is how they are able to make sense of pictorial information (Barlow, 1990; 
Messaris, 1994) and representative images have a close relationship with actual objects, which likely accounts for this preference. However, differences were seen for aesthetic appeal. The children in Group 2 showed very reliable preferences for the representative variations, but those indicated by the children in Group 1 were for the stylised options. Stylised imagery is popular in reading materials for children and is also common in media and advertising; this group of children are likely to be familiar and comfortable with it. It was also clear that the children in Group 1 thought differently about clarity and aesthetic appeal. When asked which variation he would choose to help him explain the meaning of the word to his classmates, Ethan said that he would choose the representative variation. He stated that although he liked the look of the stylised illustrations better, he thought his classmates would be better able to understand the representative images.

The children in both groups showed a strong preference for the colour illustrations and confirmed that colour is a valuable visual cue, but these preferences were less reliable when comparing the stylised illustrations than when comparing the representative. Colour would only enhance the realistic nature of the representative illustrations, which could account for the strong preference indicated for colour-representative. Stylised illustrations are common and, due to printing costs, colour is rarely seen in books designed for children with more advanced reading ability. As a result, it is likely that children are more familiar with greyscalestylised illustrations.

Although this study was limited to specific stylistic issues surrounding the use of colour and the level of detail, it has shown that children have specific ideas about what they think makes an illustration easier to understand and what will make that illustration easier for their peers. But, and as was seen with the typography, these preferences indicated by children are not always reflected in the literacy materials designed for them.

\section{Conclusion}

This study has shown that children with reading difficulties have specific opinions about the presentation of the typography and illustration in their literacy materials: what they like the look of best, think looks easier to read, and find easier to understand. Although further research is needed to clarify how spacing and size influences the reading performance of a larger sample of children with reading difficulties, and how the presentation of illustrative information affects the literacy acquisition of this group, it is important to note that it is these preferences that are likely to influence whether children will choose to read a particular book, or not. As literacy can only be gained through constant and continued practice (Byrne, 2007), it is important to consider how literacy materials can be generated that children with reading difficulties will want to read.

\section{References}

Arnheim, R. (1969). Visual thinking. London: University of California Press.

Barlow, H. (1990). What does the brain see? How does it understand? In H. Barlow, C. Blakemore, \& M. Weston-Smith (Eds.), Images and understanding. Cambridge: Cambridge University Press.

Barrington Stoke Ltd. www.barringtonstoke.co.uk [Retrieved 22 November 2008].

Burden, R., \& Burdett, J. (2005). Factors associated with successful learning in pupils with dyslexia: A motivational analysis. British Journal of Special Education, 32(2), 100-104. 
Byrne, B. (2007). Theories of learning to read. In M. Snowling, \& C. Hulme (Eds.), The science of reading: A handbook (pp. 104-119). Oxford: Blackwell Publishing Ltd.

Carney, R., \& Levin, J. (2002). Pictorial illustrations still improve student's learning from text. Educational Psychology Review, 14(1), 5-26.

Castle, S. (2004). Grover: A family of three typefaces which consider the problems and needs of the dyslexic reader. Reading: Unpublished information leaflet.

Cox, K., \& Guthrie, J. (2001). Motivational and cognitive contributions to student's amount of reading. Contemporary Educational Psychology, 26, 116-131.

Frensch, N. (2003). Read Regular: For more effective reading and writing. London: Natascha Frensch.

Goldsmith, E. (1984). Research into illustration: An approach and a review. Cambridge: Cambridge University Press.

Hillier, R. (2006). A typeface for the adult dyslexic reader. PhD Thesis, Anglia Ruskin University.

Hinchman, K. (2005). Why qualitative research continues to thrive: Jason and the politics of representation. Reading Research Quarterly, 40(1), 100-105.

Hughes, L., \& Wilkins, A. (2000). Typography in children's reading schemes may be suboptimal: Evidence form measures of reading rate. Journal of Research in Reading, 23(3), 314-324.

Hughes, L., \& Wilkins, A. (2002). Reading at a distance: Implications for the design of text in children's big books. British Journal of Educational Psychology, 72, 213-226.

Levin, J., Anglin, G., \& Carney, R. (1987). On empirically validating functions of picture in prose. In D. Willows, \& H. Houghton (Eds.), The psychology of illustration: Basic research (Vol. 1, pp. 51-85). New York: Springer-Verlag.

Messaris, P. (1994). Visual 'literacy': Image, mind, and reality. Oxford: Westview Press.

Newton, D. (1995). The role of pictures in learning to read. Educational Studies, 21(1), 119-131.

Peeck, J. (1987). The role of illustrations in processing and remembering illustrated text. In D. Willows, \& H. Houghton (Eds.), The psychology of illustration: Basic research (Vol. 1, pp. 115-151). New York: Springer-Verlag.

Reynolds, L., \& Walker, S. (2004). 'You can't see what the words say': Word spacing and letter spacing in children's reading books. Journal of Research in Reading, 27(1), 87-98.

Reynolds, L., \& Walker, S. (2006). Holes to tell which line you're on: Children's responses to line spacing in early reading books. Visible Language, 40(3), 246-267.

Strong, J. (2002). Mad Iris. Edinburgh: Barrington Stoke Ltd.

The Three Little Pigs. (2006). Ladybird's Read-it-Yourself Series. London: Ladybird Books Ltd.

Thiessen, M. (2007). An analysis of literacy materials designed for children with dyslexia. MA Dissertation, University of Reading.

Thompson, P. (2003). Consulting the customer: Publishing for dyslexics. Available from: www.sprakaloss.se/Publishing-Thompson.htm [Retrieved 10 August 2007].

Tinker, M. (1963). Legibility of print. Ames: Iowa State University Press.

Walker, S., \& Reynolds, L. (2002/03). Serif, sans serif and infant characters in children's reading books. Information Design Journal and Document Design, 11(2/3), 106-122.

Watts, L., \& Nisbet, J. (1974). Legibility in children's books: A review of research. Windsor: NFER Publishing Company Limited.

Wilkins, A. (2003). Reading through colour: How coloured filters can reduce reading difficulty, eye strain, and headaches. West Sussex: John Wiley and Sons Ltd. 


\section{Appendix 1}

Table 1: Letter, Word, and Line Spacing Used for Sets 1, 2, and 3

\begin{tabular}{|l|l|l|l|}
\hline Group 1 & Letter and Word Spacing $^{1}$ & Size $(x-H e i g h t)$ & Line Spacing \\
\hline Wide & $+50 \mathrm{em}$ & $3.5 \mathrm{~mm}$ & $15 \mathrm{~mm}$ \\
\hline Default & $0 \mathrm{em}$ & $3.5 \mathrm{~mm}$ & $11 \mathrm{~mm}$ \\
\hline Narrow & $-50 \mathrm{em}$ & $3.5 \mathrm{~mm}$ & $8.5 \mathrm{~mm}$ \\
\hline Group 2 & Letter and Word Spacing & Size $(\mathrm{x}-$ Height $)$ & Line Spacing \\
\hline Wide & $+50 \mathrm{em}$ & $2 \mathrm{~mm}$ & $9 \mathrm{~mm}$ \\
\hline Default & $0 \mathrm{em}$ & $2 \mathrm{~mm}$ & $7 \mathrm{~mm}$ \\
\hline Narrow & $-50 \mathrm{em}$ & $2 \mathrm{~mm}$ & $5.5 \mathrm{~mm}$ \\
\hline
\end{tabular}

${ }^{1}$ The letter and word spacing was measured in ems. An em is a unit of measure that is determined by the size of the type used in a given layout. For example, if the type size is 12 points than 1 em equals 12 points; if it is 24 points, than 1 em equals 24 points.

Table 2: Type Size and Line Spacing Used for Set 4

\begin{tabular}{|l|l|l|}
\hline Group 1 & Size (x-Height) & Line Spacing \\
\hline Large & $4 \mathrm{~mm}$ & $13 \mathrm{~mm}$ \\
\hline Standard & $3.5 \mathrm{~mm}$ & $11 \mathrm{~mm}$ \\
\hline Small & $2.5 \mathrm{~mm}$ & $8.5 \mathrm{~mm}$ \\
\hline Group 2 & Size (x-Height) & Line Spacing \\
\hline Large & $2.5 \mathrm{~mm}$ & $9 \mathrm{~mm}$ \\
\hline Standard & $2 \mathrm{~mm}$ & $7 \mathrm{~mm}$ \\
\hline Small & $1.5 \mathrm{~mm}$ & $5 \mathrm{~mm}$ \\
\hline
\end{tabular}


Appendix 2: Preference for Typography

Table 3: Group 1's Preferences for Legibility

\begin{tabular}{|l|l|l|l|l|}
\hline Ethan & Set 1 & Set 2 & Set 3 & Set 4 \\
\hline Session 1 & Default & Wide & Narrow & Standard \\
\hline Session 2 & Default & Narrow & Wide & Standard/Large \\
\hline Session 3 & Default/Wide & Wide & Default & Standard/Large \\
\hline Chloe & Set 1 & Set 2 & Set 3 & Set 4 \\
\hline Session 1 & Narrow & Wide & Narrow & Large \\
\hline Session 2 & Narrow & Wide & Wide & Large \\
\hline Session 3 & Default & Wide & Wide & Large \\
\hline
\end{tabular}

Table 4: Group 1's Preferences for Aesthetic Appeal

\begin{tabular}{|l|l|l|l|l|}
\hline Ethan & Set 1 & Set 2 & Set 3 & Set 4 \\
\hline Session 1 & Default & Wide & Narrow & Standard \\
\hline Session 2 & Default & Wide & Default & Standard \\
\hline Session 3 & Default & Wide & Default & Standard \\
\hline Chloe & Set 1 & Set 2 & Set 3 & Set 4 \\
\hline Session 1 & Narrow & Wide & Default & Large \\
\hline Session 2 & Default & Default & Default & Large \\
\hline Session 3 & Narrow & Wide & Narrow & Large \\
\hline
\end{tabular}


Table 5: Group 2's Preferences for Legibility

\begin{tabular}{|c|c|c|c|c|}
\hline Emma & Set 1 & Set 2 & Set 3 & Set 4 \\
\hline Session 1 & Wide & Wide & Default & Standard \\
\hline Session 2 & Wide & Default & Default & Standard \\
\hline Session 3 & Default & Default & Default & Standard \\
\hline Joshua & Set 1 & Set 2 & Set 3 & Set 4 \\
\hline Session 1 & Narrow & Default & Wide & Large \\
\hline Session 2 & Wide & Narrow & Wide & Large \\
\hline Session 3 & Wide & Wide & Default & Large \\
\hline Lily & Set 1 & Set 2 & Set 3 & Set 4 \\
\hline Session 1 & Wide & Wide & Wide & Small \\
\hline Session 2 & Wide & Wide & Wide & Small \\
\hline Session 3 & Wide & Wide & Wide & Large \\
\hline Max & Set 1 & Set 2 & Set 3 & Set 4 \\
\hline Session 1 & Wide & Wide & Wide & Small \\
\hline Session 2 & Narrow & Narrow & Narrow & Small \\
\hline Session 3 & Default & Narrow & Narrow & Small \\
\hline
\end{tabular}


Table 6: Group 2's Preferences for Aesthetic Appeal

\begin{tabular}{|c|c|c|c|c|}
\hline Emma & Set 1 & Set 2 & Set 3 & Set 4 \\
\hline Session 1 & Wide & Wide & Default & Standard \\
\hline Session 2 & Wide & Default & Default & Standard \\
\hline Session 3 & Default & Default & Default & Standard \\
\hline Joshua & Set 1 & Set 2 & Set 3 & Set 4 \\
\hline Session 1 & Wide & Default & Default & Small \\
\hline Session 2 & Narrow & Narrow & Wide & Small \\
\hline Session 3 & Wide & Narrow & Default/Wide & Small \\
\hline Lily & Set 1 & Set 2 & Set 3 & Set 4 \\
\hline Session 1 & Wide & Wide & Wide & Small \\
\hline Session 2 & Wide & Wide & Wide & Small \\
\hline Session 3 & Wide & Wide & Wide & Large \\
\hline Max & Set 1 & Set 2 & Set 3 & Set 4 \\
\hline Session 1 & Wide & Narrow & Narrow & Small \\
\hline Session 2 & Narrow & Narrow & Default & Small \\
\hline Session 3 & Default & Narrow & Narrow & Large \\
\hline
\end{tabular}

\section{Appendix 3: Preference for Illustration}

Table 7: Group 1's Preferences for Clarity

\begin{tabular}{|l|l|l|l|l|}
\hline Ethan & $\begin{array}{l}\text { Colour- } \\
\text { representative }\end{array}$ & Colour-stylised & $\begin{array}{l}\text { Level of Detail- } \\
\text { colour }\end{array}$ & $\begin{array}{l}\text { Level of Detail- } \\
\text { greyscale }\end{array}$ \\
\hline Session 1 & Colour & Colour & No preference & Representative \\
\hline Session 2 & Colour & Colour & Representative & Representative \\
\hline Session 3 & Colour & Colour & Stylised & Stylised \\
\hline Chloe & $\begin{array}{l}\text { Colour- } \\
\text { representative }\end{array}$ & Colour-stylised & $\begin{array}{l}\text { Level of } \\
\text { Detail-colour }\end{array}$ & $\begin{array}{l}\text { Level of Detail- } \\
\text { greyscale }\end{array}$ \\
\hline Session 1 & Colour & Colour & Stylised & Stylised \\
\hline Session 2 & Colour & Colour & Representative & Representative \\
\hline Session 3 & Colour & Colour & Representative & Stylised \\
\hline
\end{tabular}


Table 8: Group 1's Preferences for Explaining the Meaning of the Word

\begin{tabular}{|l|l|l|l|l|}
\hline Ethan & $\begin{array}{l}\text { Colour- } \\
\text { representative }\end{array}$ & Colour-stylised & $\begin{array}{l}\text { Level of Detail- } \\
\text { colour }\end{array}$ & $\begin{array}{l}\text { Level of Detail- } \\
\text { greyscale }\end{array}$ \\
\hline Session 1 & Colour & Colour & Representative & Representative \\
\hline Session 2 & Colour & Colour & Representative & Representative \\
\hline Session 3 & Colour & Colour & Stylised & Representative \\
\hline Chloe & $\begin{array}{l}\text { Colour- } \\
\text { representative }\end{array}$ & Colour-stylised & $\begin{array}{l}\text { Level of Detail- } \\
\text { colour }\end{array}$ & $\begin{array}{l}\text { Level of Detail- } \\
\text { greyscale }\end{array}$ \\
\hline Session 1 & Colour & Colour & Stylised & Stylised \\
\hline Session 2 & Colour & Colour & Stylised & Representative \\
\hline Session 3 & Colour & Colour & Representative & Stylised \\
\hline
\end{tabular}

Table 9: Group 1's Preferences for Aesthetic Appeal

\begin{tabular}{|l|l|l|l|l|}
\hline Ethan & $\begin{array}{l}\text { Colour- } \\
\text { representative }\end{array}$ & Colour-stylised & $\begin{array}{l}\text { Level of Detail- } \\
\text { colour }\end{array}$ & $\begin{array}{l}\text { Level of Detail- } \\
\text { greyscale }\end{array}$ \\
\hline Session 1 & Colour & Colour & Stylised & Stylised \\
\hline Session 2 & Greyscale & Greyscale & Stylised & Stylised \\
\hline Session 3 & Colour & Greyscale & Stylised & Stylised \\
\hline Chloe & $\begin{array}{l}\text { Colour- } \\
\text { representative }\end{array}$ & Colour-stylised & $\begin{array}{l}\text { Level of Detail- } \\
\text { colour }\end{array}$ & $\begin{array}{l}\text { Level of Detail- } \\
\text { greyscale }\end{array}$ \\
\hline Session 1 & Colour & Colour & Stylised & Representative \\
\hline Session 2 & Colour & Colour & Stylised & Representative \\
\hline Session 3 & Colour & Colour & Representative & Stylised \\
\hline
\end{tabular}

Table 10: Group 2's Preferences for Clarity

\begin{tabular}{|l|l|l|l|l|}
\hline Emma & $\begin{array}{l}\text { Colour- } \\
\text { representative }\end{array}$ & Colour-stylised & $\begin{array}{l}\text { Level of Detail- } \\
\text { colour }\end{array}$ & $\begin{array}{l}\text { Level of Detail- } \\
\text { greyscale }\end{array}$ \\
\hline Session 1 & No preference & No preference & Stylised & Stylised \\
\hline Session 2 & Colour & No preference & No preference & Stylised \\
\hline Session 3 & Colour & Colour & No preference & No preference \\
\hline Joshua & $\begin{array}{l}\text { Colour- } \\
\text { representative }\end{array}$ & Colour-stylised & $\begin{array}{l}\text { Level of Detail- } \\
\text { colour }\end{array}$ & $\begin{array}{l}\text { Level of Detail- } \\
\text { greyscale }\end{array}$ \\
\hline Session 1 & Colour & Colour & Representative & Representative \\
\hline Session 2 & Colour & Colour & Representative & Representative \\
\hline Session 3 & Colour & Greyscale & Stylised & Stylised \\
\hline
\end{tabular}




\begin{tabular}{|l|l|l|l|l|}
\hline Lily & $\begin{array}{l}\text { Colour- } \\
\text { representative }\end{array}$ & Colour-stylised & $\begin{array}{l}\text { Level of Detail- } \\
\text { full colour }\end{array}$ & $\begin{array}{l}\text { Level of Detail- } \\
\text { greyscale }\end{array}$ \\
\hline Session 1 & Colour & Colour & Representative & Representative \\
\hline Session 2 & Colour & Colour & Representative & Stylised \\
\hline Session 3 & No preference & Colour & Representative & Representative \\
\hline Max & $\begin{array}{l}\text { Colour- } \\
\text { representative }\end{array}$ & Colour-stylised & $\begin{array}{l}\text { Level of Detail- } \\
\text { colour }\end{array}$ & $\begin{array}{l}\text { Level of Detail- } \\
\text { greyscale }\end{array}$ \\
\hline Session 1 & Colour & Colour & Representative & Representative \\
\hline Session 2 & Colour & Greyscale & Stylised & Representative \\
\hline Session 3 & Colour & Greyscale & Stylised & Stylised \\
\hline
\end{tabular}

Table 11: Group 2's Preferences for Explaining the Meaning of the Word

\begin{tabular}{|l|l|l|l|l|}
\hline Emma & $\begin{array}{l}\text { Colour- } \\
\text { representative }\end{array}$ & Colour-stylised & $\begin{array}{l}\text { Level of Detail- } \\
\text { colour }\end{array}$ & $\begin{array}{l}\text { Level of Detail- } \\
\text { greyscale }\end{array}$ \\
\hline Session 1 & Colour & Colour & Stylised & Representative \\
\hline Session 2 & Colour & Colour & Representative & Representative \\
\hline Session 3 & Colour & Colour & Representative & Representative \\
\hline Joshua & $\begin{array}{l}\text { Colour- } \\
\text { representative }\end{array}$ & Colour-stylised & $\begin{array}{l}\text { Level of Detail- } \\
\text { colour }\end{array}$ & $\begin{array}{l}\text { Level of Detail- } \\
\text { greyscale }\end{array}$ \\
\hline Session 1 & Colour & Colour & Representative & Representative \\
\hline Session 2 & Colour & Colour & Representative & Representative \\
\hline Session 3 & Colour & Colour & Stylised & Stylised \\
\hline Lily & representative & Colour-stylised & $\begin{array}{l}\text { Level of Detail- } \\
\text { colour }\end{array}$ & $\begin{array}{l}\text { Level of Detail- } \\
\text { greyscale }\end{array}$ \\
\hline Session 1 & Colour & Colour & Representative & Representative \\
\hline Session 2 & Colour & Colour & Representative & Stylised \\
\hline Session 3 & Colour & Colour & Representative & Representative \\
\hline Max & $\begin{array}{l}\text { Colour- } \\
\text { representative }\end{array}$ & Colour-stylised & $\begin{array}{l}\text { Level of Detail- } \\
\text { colour }\end{array}$ & $\begin{array}{l}\text { Level of Detail- } \\
\text { greyscale }\end{array}$ \\
\hline Session 1 & Colour & Greyscale & Representative & Representative \\
\hline Session 2 & Colour & Colour & Representative & Representative \\
\hline Session 3 & Colour & Colour & Representative & Stylised \\
\hline
\end{tabular}


Table 12: Group 2's Preferences for Aesthetic Appeal

\begin{tabular}{|l|l|l|l|l|}
\hline Emma & $\begin{array}{l}\text { Colour- } \\
\text { representative }\end{array}$ & Colour-stylised & $\begin{array}{l}\text { Level of Detail- } \\
\text { colour }\end{array}$ & $\begin{array}{l}\text { Level of Detail- } \\
\text { greyscale }\end{array}$ \\
\hline Session 1 & Colour & Colour & Stylised & Representative \\
\hline Session 2 & Colour & Colour & Representative & Representative \\
\hline Session 3 & Colour & Colour & Representative & Representative \\
\hline Joshua & $\begin{array}{l}\text { Colour- } \\
\text { representative }\end{array}$ & Colour-stylised & $\begin{array}{l}\text { Level of Detail- } \\
\text { colour }\end{array}$ & $\begin{array}{l}\text { Level of Detail- } \\
\text { greyscale }\end{array}$ \\
\hline Session 1 & Colour & Colour & Representative & Representative \\
\hline Session 2 & Colour & Greyscale & Representative & Representative \\
\hline Session 3 & Colour & Colour & Representative & Stylised \\
\hline Lily & Colour- & Colour-stylised & $\begin{array}{l}\text { Level of detail- } \\
\text { colour }\end{array}$ & $\begin{array}{l}\text { Level of detail- } \\
\text { greyscale }\end{array}$ \\
\hline Session 1 & Colour & Colour & Representative & Representative \\
\hline Session 2 & Colour & Colour & Representative & Stylised \\
\hline Session 3 & Colour & Colour & Representative & Representative \\
\hline Max & $\begin{array}{l}\text { Colour- } \\
\text { representative }\end{array}$ & Colour-stylised & $\begin{array}{l}\text { Level of Detail- } \\
\text { colour }\end{array}$ & $\begin{array}{l}\text { Level of Detail- } \\
\text { greyscale }\end{array}$ \\
\hline Session 1 & Colour & Colour & Representative & Representative \\
\hline Session 2 & Colour & Greyscale & Representative & Representative \\
\hline Session 3 & Greyscale & Colour & Representative & Representative \\
\hline
\end{tabular}

\section{About the Authors}

Myra Thiessen

Myra Thiessen is a PhD student in the Department of Typography \& Graphic Communication at the University of Reading, UK. Her research is concerned with how visual explanations of complex verbal concepts can be used to aid in the literacy education of dyslexic children. Myra is supported by a University of Reading Overseas Postgraduate Research Studentship.

Dr. Mary C. Dyson

Mary Dyson is Myra's PhD supervisor. Mary teaches and researches into the evaluation of graphic materials in the Department of Typography \& Graphic Communication at the University of Reading, UK. 


\section{EDITORS}

Mary Kalantzis, University of Illinois, Urbana-Champaign, USA.

Bill Cope, University of Illinois, Urbana-Champaign, USA.

\section{EDITORIAL ADVISORY BOARD}

Michael Apple, University of Wisconsin, Madison, USA.

David Barton, Lancaster University, Milton Keynes, UK.

Mario Bello, University of Science, Cuba.

Manuela du Bois-Reymond, Universiteit Leiden, Leiden, The Netherlands.

Robert Devillar, Kennesaw State University, Kennesaw, USA.

Daniel Madrid Fernandez, University of Granada, Spain.

Ruth Finnegan, Open University, Milton Keynes, UK.

James Paul Gee, University of Wisconsin, Madison, USA.

Juana M. Sancho Gil, University of Barcelona, Barcelona, Spain.

Kris Gutierrez, University of California, Los Angeles, USA.

Anne Hickling-Hudson, Queensland University of Technology, Kelvin Grove, Australia.

Roz Ivanic, Lancaster University, Lancaster, UK.

Paul James, RMIT University, Melbourne, Australia.

Carey Jewitt, Institute of Education, University of London, London, UK.

Andeas Kazamias, University of Wisconsin, Madison, USA.

Peter Kell, University of Wollongong, Wollongong, Australia.

Michele Knobel, Montclair State University, Montclair, USA.

Gunther Kress, Institute of Education, University of London, London, UK.

Colin Lankshear, James Cook University, Cairns, Australia.

Kimberly Lawless, University of Illinois, Chicago, USA.

Sarah Michaels, Clark University, Worcester, USA.

Jeffrey Mok, Miyazaki International College, Miyazaki, Japan.

Denise Newfield, University of Witwatersrand, Johannesburg, South Africa.

Ernest O'Neil, Ministry of Education, Addis Ababa, Ethiopia.

José-Luis Ortega, University of Granada, Granada, Spain.

Francisco Fernandez Palomares, University of Granada, Granada, Spain.

Ambigapathy Pandian, Universiti Sains Malaysia, Penang, Malaysia.

Miguel A. Pereyra, University of Granada, Granada, Spain.

Scott Poynting, Manchester Metropolitan University, Manchester, UK.

Angela Samuels, Montego Bay Community College, Montego Bay, Jamaica.

Michel Singh, University of Western Sydney, Sydney, Australia.

Helen Smith, RMIT University, Melbourne, Australia.

Richard Sohmer, Clark University, Worcester, USA.

Brian Street, University of London, London, UK.

Giorgos Tsiakalos, Aristotle University of Thessaloniki, Thessaloniki, Greece.

Salim Vally, University of Witwatersrand, Johannesburg, South Africa

Gella Varnava-Skoura, National and Kapodistrian University of Athens, Greece.

Cecile Walden, Sam Sharpe Teachers College, Montego Bay, Jamaica.

Nicola Yelland, Victoria University, Melbourne, Australia.

Wang Yingjie, Beijing Normal University, Beijing, China.

Zhou Zuoyu, Beijing Normal University, Beijing, China.

Please visit the Journal website at http://www.Learning-Journal.com for further information about the Journal or to subscribe. 


\section{THE UNIVERSITY PRESS JOURNALS}

\section{The International
JOURNAL Of the ARTS IN SOCIETY}

Creates a space for dialogue on innovative theories and practices in the arts, and their inter-relationships with society.

ISSN: 1833-1866

http://www.Arts-Journal.com

\section{DESIGN PRINCIPLES \& PRACTICES}

Q:

Examines the meaning and purpose of 'design' while also speaking in grounded ways about the task of design and the use of designed artefacts and processes.

ISSN: 1833-1874

http://www.Design-Journal.com

\section{THE GLOBAL STUDIES JOURNAL}

Maps and interprets new trends and patterns in globalisation.

ISSN 1835-4432

http://www.GlobalStudiesJournal.com

\section{The Intermational OU LEARNING}

Sets out to foster inquiry, invite dialogue and build a body of knowledge on the nature and future of learning.

ISSN: $1447-9540$

http://www.Learning-Journal.com

\section{The International $f_{\text {the }}$ INCLUSIVE MUSEUM}

Addresses the key question: How can the institution of the museum become more inclusive? ISSN 1835-2014

http://www.Museum-Journal.com

\section{The Intemational
JOURNAL Of ENVRONMENTAL CUIUURAL}

Draws from the various fields and perspectives through which we can address fundamental questions of sustainability.

ISSN: 1832-2077

http://www.Sustainability-Journal.com

\section{UBIQUITOUS LEARNING}

An International Joum

Investigates the affordances for learning in the digital media, in school and throughout everyday life.

ISSN 1835-2030

http://www.ULJournal.com

\section{The Ineremational $f_{i \text { ibe }}$ BOOK}

Explores the past, present and future of books, publishing, libraries, information, literacy and learning in the information society. ISSN: 1447-9567

http://www.Book-Journal.com

\section{The International
JOURNAL of DIVERSITY in ORGANISATIONS.
COMMUNIIIS \& NATIONS}

Provides a forum for discussion and builds a body of knowledge on the forms and dynamics of difference

and diversity.

ISSN: 1447-9583

http://www.Diversity-Journal.com

\section{JoURNAL Of in HUMANITIES}

Discusses the role of the humanities in contemplating the future and the human, in an era otherwise dominated by scientific, technical and economic rationalisms.

ISSN: 1447-9559

http://www.Humanities-Journal.com

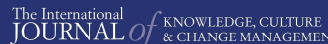

Creates a space for discussion of the nature and future of organisations, in all their forms and manifestations.

ISSN: 1447-9575

http://www.Management-Journal.com

\section{The International}

Discusses disciplinary and interdisciplinary approaches to knowledge creation within and across the various social sciences and between the social, natural and applied sciences. ISSN: 1833-1882

http://www.Socialsciences-Journal.com

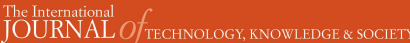

Focuses on a range of critically important themes in the various fields that address the complex and subtle relationships between technology, knowledge and society.

ISSN: $1832-3669$

http://www.Technology-Journal.com

\section{JOURNAL $O f_{\text {the }}$ World Universities Forum}

Explores the meaning and purpose of the academy in times of striking social transformation.

ISSN 1835-2030

http://www.Universities-Journal.com 